\title{
Uma Leitura da Escrita Consolatória Senequiana
}

\author{
Maria de Fátima Veloso
}

\begin{abstract}
Resumo
Este ensaio mostra a estrutura do gênero literário das Consolações e algumas das variações introduzidas por Sêneca aos recursos retóricos clássicos na escrita do Ad Helviam - De Consolatione.
\end{abstract}

Palavras-chave: Sêneca. Consolações. Variações. Ad Helviam.

O desejo de encontrar o remédio eficaz para abrandar o sofrimento alheio é tão antigo no mundo quanto o homem. Na Odisséia de Homero (Odisséia, IV, 219-226), encontramos um registro através do pharmacon, substância que Helena mistura ao vinho para aliviar a tristeza de parentes e amigos dos heróis que haviam morrido na guerra. Entre os gregos, porém, a partir da teoria socrática da natureza do homem como psyché, além dos medicamentos físicos, empreende-se a busca de uma adequada terapia para os males da alma. Platão tinha plena convicção de que os males do homem não podiam ser curados apenas com o remédio para o corpo, mas também para a alma. Ao abordar metaforicamente o tema da saúde humana, conta-nos sobre o jovem Cármides, que sofria de terríveis dores de cabeça, ao qual Sócrates apresentase com uma receita:

Tratava-se de uma erva que devia ser acompanhada por um encantamento; e se alguém o pronunciava enquanto se servia dela, a droga resultava eficaz; caso contrário, a erva não trazia nenhum benefício. (PLATÃO. Cármide, 155 E apud REALE, 2004, p. 14)

Segundo Reale (2004) a erva simbolizava a medicina convencional e o encantamento era um medicamento espiritual, ou seja, a palavra filosófica que educava para a moderação e para a virtude da prática da justa mensura.

A função medicamentosa da palavra ganha força: em Ésquilo encontramos a menção de "palavras que curam": l̉atroì logoi: e em Eurípedes, a recomendação de que "para aquele que sofre doce é a palavra de um amigo". Sem dúvida, as primeiras expressões consolatórias como arte surgem através da poesia - em Homero (Ilíada, XXIV, 518-551), assistimos ao esforço de Aquiles para consolar Príamo pela dor da perda do filho, também "lemos em Plutarco que Antímaco era conhecido entre os elegíacos por uma elegia que compôs para si mesmo, por ocasião da morte de sua amada" (VAN RAIJ, 1986, fl. 24) - mas, aos poucos, da identificação com o sofrimento de seus semelhantes e da tentativa de apartar-lhes a dor, o dom humano de consolar evolui e dá lugar a um gênero literário. 
Adrados organiza, segundo critérios próprios, os fragmentos da elegia de Arquíloco a Péricles, que se constitui no primeiro exemplar do gênero literário de Consolação sob essa forma. No tumultuado período da colonização de Tasos, um navio cheio de guerreiros afundou e entre os mortos estava o irmão de Péricles e cunhado de Arquíloco. Tal fato mobiliza a sensibilidade de Arquíloco para a seguinte composição:

\author{
8 - Em tudo está o homem sujeito à Fortuna e ao Destino \\ $<$ e, assim, agora pereceu nosso parente e seus companheiros $>$ \\ 12 - Em vão invocaram a Leucotea na tempestade \\ <pois após uma luta extenuante o mar os devorou, retendo seus cadáveres> \\ $10 a$ - O que faz mais dolorosa sua perda. \\ 11 - Porém, resignemo-nos ante a prova a que nos submete Posseidon \\ $<$ e tenhamos valor $>$ \\ 7 - É certo que sofremos uma grande desgraça e toda a cidade \\ assim pensará: Porém isto é próprio do destino \\ humano. Ponde-lhe o único remédio que tem: a resignação. \\ <assim, farei eu, tratando de esquecer minha aflição> \\ $10 \mathrm{~b}$ - Pois nem meu pranto corrigirá nada, nem minha alegria será causa de males \\ maiores. (ADRADOS, 1981, p. 180, tradução nossa.)
}

Nesse trabalho, Arquíloco caracteriza as unidades que compõem verdadeiramente o gênero: explicita a impotência humana; exemplifica-a através da descrição do naufrágio, da morte do cunhado de Péricles e da dor que provocou a este e a si próprio e, por último, propõe a resignação como único remédio possível para a perda.

A literatura latina também exibe consolações em versos: de autor desconhecido é uma consolatio ad Liviam, escrita a essa dama por ocasião da morte do filho Druso, mas por muitos atribuída a Ovídio. O mesmo Ovídio consola o amigo Galeão pela perda da mulher (OVÍDIO, Pont. 4,11) e Estácio compõe outras quatro (ESTÁCIO, Sil. 2,1 e $6 ; 3,3$ e 5,1 ).

Além de se expressar em poemas, o discurso consolatório pode ser encontrado em outras formas: diálogos, exortações filosóficas e longos ensaios; a cultura popular deixa sua contribuição por meio de inúmeros epitáfios; um exemplo da consolação na sátira chega-nos por Juvenal e há ainda farto material epistolográfico.

Ao que tudo indica, a carta nasceu com a escrita, pois esta não era utilizada apenas para anotações contábeis, mas também para comunicar pensamentos e desejos a pessoas distantes; contudo, o intercâmbio epistolar no mundo antigo era um fato raro e apenas utilizado em situações gravíssimas. As dificuldades para fabricação e obtenção do material de suporte para a escrita, o aprendizado da escrita restrito a grupos seletos, as dificuldades de trânsito entre grandes distâncias faziam da carta privada um meio de comunicação esporádico. Essa correspondência é, ainda em nossos dias, um meio de comunicação que guarda estilo e argumento particulares e característicos de quem a escreve, não é muito longa e compreende uma saudação inicial, o texto da carta e as despedidas finais. De acordo com Cícero, ela não é um monólogo, mas a metade de um diálogo, e assim o justifica ao escrever ao irmão Quinto: cum tua lego te audire et...cum ad te scribo, tecum loqui uideor.(CÍCERO, Q. Frat. I, XVI,45)

Em Roma, a arte consolatória ganhou maior vigor no final da República e principalmente no Império. Nessa época, a carta de consolação tornou-se um instrumento habitual, todavia, pode-se constatar que, amalgamada à tradição, de modo geral, assemelhavam-se umas às outras porque estavam obrigadas ao mesmo plano de construção: na introdução, o autor anunciava os males que pretendia tratar e os remédios que iria utilizar; a consolação, propriamente dita, era dividida em duas 
partes maiores: a primeira tratava das causas da aflição, a segunda, da pessoa aflita e, por último, a conclusão. Outras convenções estabeleciam que os preceitos antecedessem os exemplos e que as consolações se baseassem em exemplos históricos. É, no entanto, incorreto pensar que as cartas consolatórias se resumissem a uma obra de confecção simples e de arranjo predeterminado. Longe de ser uma carta privada, esses pequenos tratados além de assumirem as marcas de quem os escreve, permitem também toques de originalidade nos argumentos de convencimento à pessoa a qual se dirige. Sêneca revela:

Scio a praeceptis omnes qui monere aliquem uolunt, in exemplis desinere. Mutari hunc interim morem expedit. Aliter enim cum alio agendum est: quosdam ratio ducit; quibusdam nomina clara opponenda sunt et auctoritas quae liberum non relinquat animum (SÊNECA. Ad Marciam, 2,1).

Sei que todos aqueles que desejam exortar alguém começam com preceitos e terminam com exemplos. Convém, de quando em quando, que este costume seja mudado. É necessário, pois, agir de maneira diversa, segundo as diferentes pessoas: a alguns, a razão conduz; a outros, devem-se apresentar nomes ilustres e uma autoridade que não deixe livre o espírito.

$\mathrm{Na}$ carta senequiana Ad Helviam - De Consolatione, escrita à mãe quando esteve exilado na Córsega, temos um exemplar de sua capacidade inovadora. Essa produção enquadra-se perfeitamente nos moldes da Consolatio tradicional. O exordium, início do discurso, subdivide-se em capitatio benevolentiae e partitio. A capitatio benevolentiae, trecho que visa seduzir os ouvintes obtendo sua cumplicidade, ocupa todo o capítulo I e neste Sêneca tenta mostrar-se como a melhor pessoa para consolar a mãe, uma vez que ele também experimenta sofrimento.

$\mathrm{Na}$ segunda parte, a confirmatio, trecho de caráter moral e que se inicia no capítulo $\mathrm{V}$, ele expõe seus argumentos e consola enumerando ações passadas.

Por fim, o epilogus, momento de síntese não apenas do enredo, mas também de seu pensar filosófico, preenche todo o capítulo XX.

A engenhosidade do autor, entretanto, não permite que as características do seu trabalho se atenham única e exclusivamente ao que é comum ao gênero, pois, através dele organiza sua experiência de exílio. Este espaço percebido, ainda que pouco narrado, é também motivo da escrita e a escritura, ao mesmo tempo, presta-se à persuasão e à exteriorização de suas lembranças íntimas. Da mesclagem entre o retoricismo e o lirismo das recordações pessoais, da realidade e do imaginário, da meditação e da exposição pública de suas considerações, nasce uma obra ficcional, em tom confessional e estilo privado, que cativa o leitor.

Dialoga com um ouvinte imaginário e na função de médico de alma, disposto a encontrar o remédio mais eficaz para abrandar o sofrimento alheio, aponta o motivo da dor e esclarece o plano que será utilizado para combatê-la; explicita a impotência humana e, como filósofo que é, propõe, através de argumentação em que mescla preceitos filosóficos de escolas diferentes, a melhor maneira para atenuá-la; oferece consolo e ensina, por meio de exemplos, lições de prudência, paciência, humildade, determinação e amor. Espelha-se no passado, atualiza-o no presente e vislumbra o futuro de modo confiante. Estas são propriedades que eternizam o sentido de atualização da obra.

O autor mescla o particular ao que é comum a todos os humanos e, para atrair a credibilidade do leitor, alterna o emprego de figuras retóricas tradicionais (poliptoto, quiasmo, retificação, geminatio, zeugma, hipérbato, homeoteleuto, paranomásia, ironia, diminutivo pejorativo, antítese, metonímia, anáfora e, principalmente, 
metáfora) a recursos gramaticais que não podem deixar de ser considerados partícipes do contexto de argumentação retórica.

$\mathrm{Na}$ maioria das vezes, essas construções gramaticais surgem em benefício da diatribe. No exemplo abaixo, vê-se a utilização de quid quod, formulação de valor usual, vulgar, em lugar de seu correspondente quid dicam de eo quod.

Quid quod nouis uerbis nec ex uulgari et cotidiana sumptis allocutione opus erat homini ad consolandos suos ex ipso rogo caput alleuanti? $(1,3)$

Além disso, eram necessárias novas palavras, não extraídas da linguagem nem vulgar nem cotidiana, a um homem que erguia a cabeça da própria pira para consolar os seus?

Os elementos gramaticais, no entanto, não se vinculam apenas a esse tipo de estratégia. Uma pergunta introduzida pela partícula an deixa expressa grande dúvida e conduz o opositor à reflexão e os imperativos imprimem força expressiva maior ao discurso.

An uestem ac domum desideraturus est exsul?

Acaso o exilado precisará de casa e vestimenta?

Respice fratres meos, quibus saluis fas tibi non est accusare fortunam.(18,1). Volta-te para meus irmãos; enquanto forem vivos, não te é permitido acusar a sorte.

Os exempla são expostos com freqüência e deixam à mostra proposições que devem ser imitadas, mas um recurso a mais é utilizado por Sêneca: a reversão do foco do senso comum. Neste caso, a vítima torna-se o beneficiado:

Quis usque eo ad conspiciendam ueritatem excaecatus est, ut ignominiam putet Marci Catonis fuisse duplicem in petitione praeturae et consulatus repulsam? ignominia illa praeturae et consulatus fuit, quibus ex Catone honor habebatur. $(13,5)$

Quem pode ser tão cego diante da verdade que julgue uma dupla desonra de Marco Catão ter sido a derrota de sua candidatura à pretoria e ao consulado? Tal vergonha foi para a pretura e para o consulado, os quais seriam honrados por Catão.

A capacidade criativa de Sêneca promove, ainda, importante mutação no significado da palavra transportationes. Advinda do verbo transporto, este tem como sentido primeiro: "transportar", "levar para outro lado". Em César (De bello Gallico), aparece com significado de "deportar", "desterrar", "exilar"; no entanto, surge na escrita senequiana com o significado de "migrar".

Omnes autem istae populorum transportationes quid aliud quam publica exsilia sunt? ( 7 , 5)

Então, que são todas essas migrações de povos senão exílios coletivos?

Esses elementos geradores de persuasão são dispostos de modo premeditado e cuidadoso, criando uma atmosfera que flutua entre a doce ternura, advinda das lembranças ligadas à família, à extremada firmeza na explicitação de suas convicções filosóficas.

Deixa evidente sua intenção de capturar a atenção do leitor e evitar o tédio. Permeia o texto filosófico com fórmulas advindas da oratória popular, cria ambiente de expectativa, de dúvida e de reflexão. As perguntas retóricas aguçam a curiosidade, as menções históricas resgatam a perfeição dos antepassados e os exemplos visam a sensibilização para a busca da boa conduta. Certa emoção surge diante dos questionamentos aflitivos da mãe e o tom se ameniza. Por fim, oferece conselhos com 
força imperativa e sintetiza idéias sob a forma de meditação. Esse todo ordenado garante a clareza do texto e o envolvimento do ouvinte.

Acrescente-se a isso a inclinação natural de Sêneca à inovação. Sabedor da singularidade de seus escritos, ele próprio afirma ter seu selo pessoal e imprimir sua identidade em tudo que escreve. As virtudes senequianas deixam à mostra o espírito arrojado e futurista desse homem que se tornou em um dos maiores representantes da literatura latina da Antigüidade.

Abstract

This essay shows the structure of the literary genre of the consolationes and some of its variations introduced by Seneca based on rhetorical elements in Ad Helviam - De Consolatione.

Key words: Sêneca. Consolationes. Variations. Ad Helviam.

Referências

ADRADOS, Francisco Rodriguez. La elegia a Pericles de Arquiloco. In: _. El mundo de la lírica griega antigua. Madrid: Alianza Editorial, 1981.

ARISTÓTELES. A arte retórica e a arte poética.Tradução de Antonio Pinto de Carvalho. Rio de Janeiro: Edições de Ouro, [1992?].

CICERÓN. Correspondance. $52^{\mathrm{e}}$ éd. Texte etabli et traduit par L.A. Constans. Paris: Les Belles Lettres, 1962.

FERRARI, Franco et al. Dizionario della civiltà classica. Milano: Biblioteca Universale Rizzoli, 1993.

HARVEY, Paul. Dicionario Oxford de literatura clássica grega e latina. Tradução de Mário da Gama Kury. Rio de Janeiro: J. Zahar Ed., 1987.

HOMERO. Ilíada. 7.ed. Tradução de Carlos Alberto Nunes. Rio de Janeiro: Ediouro, 2001.

HOMERO. Odisséia. Tradução de Carlos Alberto Nunes. Rio de Janeiro: Ediouro, 1997.

LAUSBERG, Heinrich. Elementos de retórica literária. 4. ed. Tradução, prefácio e aditamentos de R. M. Rosado Fernandes. Lisboa: Fundação Calouste Gulbenkian, [s.d.].

REALE, Giovanni. La filosofia di Seneca come terapia dei mali dell'anima. 3. ed. Milano: Tascabili Bompiani, 2004.

SCARPAT, G. L'Epistulografia. In: Introduzione allo studio della cultura classica. Milano: Azorate, 1961.

SENECA. Consolations. In: SENECA. Dialogues. Tradução de René Waltz. Paris: Les Belles Lettres, 1942. v.3. 
SENECA. Consolazione ad helviam. Commento e note di Innocenzo Negro. Torino: Chiantore, 1945.

SENECA. Consolazione a mia madre Elvia. Introduzione, traduzione e note a cura di Maria Salanitro. Roma: Edizioni Dell'Ateneo, 1971.

VAN RAIJ, Cleonice F. de Mendonça. As consolações de Sêneca. 1986. Dissertação (Mestrado em Letras) Faculdade de Filosofia, Letras e Ciências Humanas, Universidade de São Paulo, São

Paulo, 1986. 